\title{
An Investigation and Countermeasures of Student Attendance of Correspondence Departments of Adult Education Colleges and Universities
}

\author{
Ning Zhixuan \\ Continuing Education College of Yanshan University \\ China, Qinhuangdao 066004
}

\begin{abstract}
Student attendance rate in adult education colleges and universities is generally low, which exerts negative influence on teachers' initiative of teaching and students' academic performance. Nearly all of the colleges have been attempting various measures to improve the situation, but with little effect. Consequently, it has always been an unsolved problem of adult education schools. This paper makes an investigation into student attendance rate and the teaching modes favored by students, makes an analysis of their causes, and comes up with their solutions.
\end{abstract}

Keywords-adult education, attendance rate, investigation, credit system

\section{INTRODUCTION}

The fact that Student attendance rate is rather low exists universally and indisputably in adult education colleges and universities. One of the difficult problems that have been perplexing educators over the years in adult education is how to change the current situation with the purpose of improving teaching and learning quality and really fulfilling the functions of education. The solution of this problem is directly related to the healthy, sustainable, and methodical development of adult education. It is already a rather long time that the adult education schools have been looking for ways out and countermeasures to deal with this difficult situation. Nevertheless the outcome is not satisfactory, and with little effect. Contrary to their expectation, some measures cause teaching and learning quality to lapse in stagnation, even retrogression. In light of the distinctive features of adult students, it is not sufficient to simply strengthen management and to stress discipline in their pursuit of higher attendance rate. As a matter of fact, to set out on the reform of teaching system and modes, to change the current teaching management mode to build the mode of classified training, and to scientifically modify teaching plans, all this can contribute to the solution which is badly in need.

\section{THE CONFLICT BETWEEN WORK, STUDY, AND DAILY LIFE OF ADULT EDUCATION STUDENTS.}

\section{A. The conflict between work and study of adult students.}

Adult education students, most of whom are graduates with diplomas of high school, technical school, and college for special training, are usually the mainstay at the forefront of production. Most of the enterprises and institutions the students work with have no holidays, even weekends, therefore their presence at work is indispensable, one for one post, and no substitute. Even though some of them can ask a leave, it usually means a unfavorable effect on their welfare and income, for instance, a deduction of 200 yuan in salary for one leave, or a month of labor without payment for two or more than two leaves, even the loss of the present job which is really hard to secure. Therefore, for some students it is even better to lose the diploma of adult education than risk losing the job.

\section{B. The conflict between study and household affairs of adult education students.}

Adult education students are a special group whose age ranges from 25 to 40 . They shoulder the pressure from engaging their work and from supporting their family, their aging parents and their young children. Most of them would not have the luxury of spending some off hours recharging and pursuing further studies, but for a pay rise, a promotion, or meeting with the rigid requirement of diploma from work.

\section{AN INVESTIGATION OF TEACHING MODES FAVORED BY ADULT EDUCATION STUDENTS.}

In order to further probe into the concrete causes of low attendance rate of the adult students, and to know their real thoughts and requirements of their expected teaching modes, this paper conducts a questionnaire amongst the 1968 adult students from all the classes and grades of some college about teaching modes, including the current modes and those methods they expect of. (See table 1).

TABLE I. TEACHING MODES FAVORED BY ADULT EDUCATION STUDENTS.

\begin{tabular}{|c|c|c|}
\hline $\begin{array}{c}\text { Serial } \\
\text { No. }\end{array}$ & Modes & consent percentage \% \\
\hline 1 & Classes on weekends & 49.6 \\
\hline 2 & $\begin{array}{c}\text { Intensive classes in summer and } \\
\text { winter vacations }\end{array}$ & 2.6 \\
\hline 3 & $\begin{array}{c}\text { students' self-study with teachers' } \\
\text { provision of study outline }\end{array}$ & 47.8 \\
\hline 4 & teaching modes advised & 0 \\
\hline
\end{tabular}

All in all, there are, up to now, the three teaching modes mentioned above about adult education (namely, correspondence learning, and evening college courses not included in this paper), no other alternatives. Having face-to- 
face classes on Saturdays and Sundays is the common practice in adult education colleges. The survey shows that nearly half of the respondents agree with this mode. Anyhow, this table also shows that their actual attendance rate is much lower than $49.6 \%$ in implementing this mode. This result might arise from their frivolous carelessness attitude towards the questionnaire. In fact, many students think that it should be such a mode since it is written in black and white in the admissions brochures, and attending classes is simply at their discretion. They still believe that despite their low attendance rate, they must be allowed to have the examinations and be granted the diploma to graduate, because they have paid their tuitions. As for the schools and teachers, they might be thought not playing its part in teaching and it is certainly not wise if they take the second and third modes listed in table 1 . Therefore it is justifiable to have a further exploration into the first mode listed in table 1 .

\section{A SURVEY OF ATTENDANCE RATE OF ADULT EDUCATION STUDENTS.}

In order to have an accurate knowledge of the actual attendance rates of the adult students, this paper makes a follow-up survey of those students from some of the representative majors of an adult college from their entrance to the college through their graduation. The subjects were those whose entered the college in March of 2011, and graduated in January of 2014, from 10 representative majors. The results are the student attendance rates of all the courses offered in each school term, and constitute a complete teaching cycle. The numbers of the students vary because of the occurrence of dropouts, and the teaching sectors of graduation design and defense are not included in the statistics. (See table 2. Note: AR represents attendance rate; EEA stands for the major of Electrical Engineering Automation; MDA is for the major of Mechanical Design Automation; CST stands for Computer Science and Technology; CET is for Construction Engineering and Technology; CE is for Civil Engineering; MMA stands for Machinery Manufacturing Automation; $\mathrm{M}$ is for Mechatronics; $\mathrm{EE}$ is for Environment Engineering; BA stands for Business Administration; A stands for Accounting).

This survey shows that student attendance rates in the first school term are relatively higher than the following ones, and the rates decrease successively with the passage of time, and it is not rare to see a class with a teacher waiting for students for two hours, feeling agitated and frustrated with no one coming to the class. Therefore, teachers might be very pleased to see one or two come to class, which will be the boast for teachers also for quite a long time. The causes of this awkward situation may be the following ones:

A. Adult education students have their own distinctive features in status. Most of them are between 25-40 years old, they have to exert themselves to juggle between work, study, supporting the old, and raising the young. The result is that they have to squeeze out some time to come to school. Faced with the harsh ethical demands of their enterprises together with the conscientious family duty, the students might feel very difficult to find a better way to solve the dilemma for the time being.
$B$. The purpose of study of the adult students is complicated. They come to school again not just for the acquisition of knowledge, sometimes they are obliged to study for wanting of promotion, better salary, or simply the demand of a degree by their enterprises.

$C$. The importance attached to the diploma of adult education by society is not as great as that to other educational programs, and it is completely incomparable to that of a regular institution of higher education. People may think owning an adult education diploma might be of some help, but without it, one has nothing important to lose. Moreover, some graduate schools do not admit students with adult education diplomas, which is really detrimental to their enterprising spirit in pursuing still further studies.

$D$. There is a great discrepancy between the courses offered by the school and the actual productive requirements of the student as an employee in an enterprise. Generally speaking, adult education colleges just directly take from the regular institutions of higher education their teaching modes, curriculum design, and textbooks. Therefore they do not have their own teaching methodology, which should be fit for the requirements of adults' characteristics and adult education. The fact is that learning content is divorced from actual demand of work greatly reduces students' learning initiative and enthusiasm.

$E$. From the perspective of the management of an adult education college, quite a lot of measures have been attempted, such as the basic requirement of minimum attendance rate, the counselor's supervision of the class at each teaching session, the classroom teacher's careful check of attendance, and the teaching supervisor's inspection of class, etc. Nevertheless, for miscellaneous reasons, all the educators concerned, the counselor, the classroom teacher, or whoever they are, might feel impotent. So are the adult education colleges as a whole.

$F$. Soon after the students are admitted to the adult education school, they get accustomed to its environment, and come to know its system and its management. They also get to know each other well or at least are on familiar terms. It is easy and convenient for them to contact each other, to take turns to come to class just like working shifts in their enterprises. Worse still, some students even find substitutes to attend classes. One can imagine the quality of learning.

\section{SPECIFIC COUNTERMEASURES}

\section{A. Break the simplistic traditional teaching mode, and change the academic year for Credit.}

Text heads organize the topics on a relational, hierarchical basis.[1] For example, the paper title is the primary text head because all subsequent material relates and elaborates on this one topic.[2] If there are two or more sub-topics, the next level head (uppercase Roman numerals) should be used and, conversely, if there are not at least two sub-topics, then no subheads should be introduced. Styles named "Heading 1," "Heading 2," "Heading 3," and "Heading 4" are prescribed. 


\section{B. Establish the classified teaching mode.}

Firstly, for those who can not come to attend classes for reasons of work or household affaires, offer them learning materials which are not just some textbooks, but experience and methods practical in actual production and carefully generalized and refined by teachers for each course, thus, the students can take initiative to study on their own at home or at work. Secondly, for those who can spare time to come to school to participate in the face-to-face teaching, it is also necessary to know their real needs to impart the knowledge that is practical and can help solve problems in work and life. To some extent, more importance can be attached to practice than purely theoretical introduction and it better to combine with cases from their work, and to encourage students to introduce for the class' reference the problems from their own working experience, how they find them, how they solve them, and what are the effects, etc.

\section{Modify the teaching plan.}

Offer courses in line with the actual needs of the adult students in production, and eliminate courses which are unnecessary, repeated, outdated, and particularly, irrelevant to their jobs. The schools still need to write or compile or use textbooks which conform to the characteristics of adult education, with stress on application and practice. Specifically, the textbooks should increase application examples, and at the same time reduce the amount of purely theoretical analysis, with a focus on problems people cared about and easily pop up. Thus, the adult students can actively devote themselves to their study in adult education schools and improve their study effect.

\section{REFERENCES}

[1] Feng Jinping.Implementation Vision of Credit System in Adult Higher Education of Tianjin Binhai Vocational Institute. Science and Technology Information[J]. Jinan: Science and Technology Information Press. 2008, (14)

[2] Wang Jialin. Reform and Exploration of Credit System of Teaching of Adult Education. China Adult Education[J]. Jinan: Higher Education Press. 2006, (7) 